p. 180. Francofurti, 1599; H. Billingsley, the first English translation of the "Elemerits of Euclid," Fol. 42. (London, 1570); N. Tartalea Brisciano, "Euclide," Fol. 32. (Venetia, $1565)$; J. P'eletarius, "In Fuclidis Elementa Geometrica Demonstrationum Libri sex." Prop. 32. Appendix a Campano, pp. 33, 34. (Iugduni, 1557).

It is much to be regretted that in this country so little im. purtance is attached to the history of mathematics; otherwise, such mistakes as those mentioned by .Mr. Tucker would not be repeated from one text book to another.

Galway, November I 7.

(iforga J. Aimmax.

\section{Instruments of Precision at the Paris Exhibition.}

I. your issue of November I5 (p. 61) is an account of "Instruments of Precision at the P'aris Fxhilition," in which it is stated that a catalogue of 250 pages has been prepared by the German Association of Mechanicians and Opticians. May I ask you to state in some future issue how that catalogue can be obtained, as I am anxious to get a copy of it ?

H.M.S. Fritannia, Dartmouth, November 21 . E. T. WARNER.

I AM much interested in the article in the number of NATt'RE for November 15, on optical and other instruments at the Paris Exhibition. Although I visited the exhibition, I did not see the exhibit, as I went too soon after the opening. I should much like to obtain the catalogue mentioned. Will you kindly tell me where I should be able to obtain one by writing for it?

H. DAVIUGE.

Seafield Park College, Crofton, Ilants, November 17.

[For information as to the German Catalogue of Scientific Instruments, application should be made to Dr. Kohert Drnsten, Bureau de l'Exposition alleinande des Instruments de P'recision, Classe 15, Section 3, Exposition Universelle, Paris. If I)r. Drosten is not in Paris, letters will probably be forwarded. The secretary of the German Committee of Management is Prof. St. Lindeck, Reichsanstalt, Charlottenburg, Berlin, who no doubt would send a catalogue.-ED. NatukE.]

ON SOLAR CHANGES OF TEMPERATURE AND VARIATIUNS IN RAINFALI. IN THE REGION SURROUVDING IHE INDIAN $O C E A N^{1}$

I.

THE fact that the abnormal behaviour of the widened lines in the spectra of sunspots since i $89+$ had been accompanied by irregularities in the rainfall of India sug. gested the study and correlation of various series of facts which might be expected to throw light upon the subject.

The conclusions alieady arrived at from bringing together the results of several investigations undertaken with this view may be stated as follows:-

(I) It has been found from a discussion of the chemical origin of lines most widened in sunspots at maxima and minima periods that there is a considerable rise above the mean temperature of the sun around the years of sunspot maximum and a considerable fall around the years of sunspot minimum.

(2) It has been found from the actual facts of rainfall in India (during the S.W. monsoon) and Mauritius, between the years 1877 and 1886,2 as given by Blanford and Meldrum, that the effects of these solar changes are felt in India at sunspot maximum, and in Mauritius at sunspot minimum. Of these the greater is that produced in the Mauritius at sunspot mininum. The pulse at Mauritius

1 By Sir Norman Lorkyer, K.C.B., F.R.S.. $\varepsilon$ nd W. J. S. Lockyer, M.A. (Camb.), Ph. D. (Gütt.). Paper read before the Ruyal Scxiety on November 22.

2 This period was selected lecause the Kensington obsersations of widened lines only began in 1879 , ant: the collected rainfall of India has only been published to 1886 .

$$
\text { NO. I622, VOL. } 63]
$$

at sunspot minimum is also felt in India, and gives rise generally to a secondary maximum in India.

India therefore has two pulses of rainfall, one near the maximum and the other near the minimum of the sunspot period.

(3) It has been found that the dates of the beginning of these two pulses on the Indian and Mauritius rainfall are related to the sudden remarkable changes in the behaviour of the widened lines.

(4) It has been found from a study of the Famine Commission reports that all the famines therein recorded which have devastated India during the last halt century (we have not yet carried the investigation further back) have occurred in the intervals between these two pulses.

(5) It has been found from the investigation of the changes in (1) the widened lines, (2) the rainfall of India and $(3)$ of the Mauritius during and after the last maximum in 1893 that important variation's from those exhibited during and after the last maximuin of 1883 occurred in all three.

It may be stated at the same time that the minimum of $1888-1889$ resembled the preceding minimum of 1878 1879

(6) It has been found from an investigation of the Nile curves between the years 1849 and 1878 that all the lowest Niles recorded have occurred between the same intervals.

(7) The relation of the intervals in question to the droughts of Austratia and of Cape Colony, and to the variations in the rainfall of extra tropical regions generally has not yet been investigated. We have found, however, a general agreement between the intervals and the rain fall of Scotland (Buchan), and have traced both pulses in the rainfalls of Córdoba (Davis) and the Cape of Good Hope.

(8) We have had the opportunity of showing these results to the Meteorological Reporter to the Government of India and Director-Ceneral of Indian Observatories, John Eliot, Esq., C.I.E., F.R.S., who is now in England, and he allows us to state his opinion that they accord closely with all the known facts of the large abnormal features of the temperature, pressure and rainfall in India during the last twenty-five years, and hence that the inductions already arrived at will be of great service in forecasting future droughts in India.

Solar Physics Observatory, October 26.

\section{AIJINDLin.}

Since Meldrum and one of us called attention, in 1872 to a possible connection between sunspots and rainfall, there has been a large literature upon the subject which it is not necessary for us to analyse ; it may be simply stated that, in spite of the cogent evidence advanced since, chiefly by Meldrum, and in later years by $\mathrm{Mr}$. Hutchins, ${ }^{1}$ it is not yet generally accepted that a case for the connection has been made out.

What has been looked for has been a change at maximum sunspots only; the iclea being that there might be an effective change of solar temperature, either in excess or defect, at such times; and that there would be a gradual and continuous variation from maximum to maxinuun.

At the same time, it is possible that the pressure connection, first advanced by Chambers, is now accepted by meteorologists as a result of the recent work of Eliot.

The coincidence, during the last few years, of an abnormal state of the sun with abnormal rain in India, accompanied by the worst famine experienced during the century, suggrested to us the desirability of reconsidering the question, especially as we have now some new factors at our disposal. These have been revealed by the study, now extending over twenty years, of the widened lines in sunspots, which suggested the view that two effects ought to be expected in a sunspot cycle instead of one.

1 "Cycles of Drought and Good "eas $n \leqslant$ in South Africa, 1889 ." 